\title{
“Daltexpharma": A Case Addressing Potential Pharmaceutical Cargo Theft
}

\author{
Tiffany M. Marchione, (student author)'; Nile M. Khanfar, PhD, MBA ${ }^{1}$; Bahaudin G. Mujtaba, (faculty supervisor) ${ }^{2}$; David Loudon,
} (faculty supervisor) $)^{3}$

${ }^{1}$ Nova Southeastern University, College of Pharmacy; ${ }^{2}$ Nova Southeastern University, Huizenga College of Business and Entrepreneurship; ${ }^{3}$ Samford University, Brock School of Business

\section{Case Synopsis}

This paper is provided as an innovative resource for those in the academic and training arenas to use as a case example in discussing the problem of pharmaceutical cargo theft. The case delves into the worldwide, on-going dilemma of pharmaceutical trucking cargo theft losses and the effects of such theft. For those unfamiliar with the case method of instruction, the paper's ending may be rather unsettling. But that is where the student's learning and faculty instruction process come together. Typically, students (whether in teams or individually) will fully develop their responses based on the queries provided at the end. Faculty may then proceed in any number of ways to elicit the students' insights in a classroom setting.

For decades the pharmaceutical industry has been plagued with a plethora of criminal acts that impact the daily processes and procedures of operations. Pharmaceutical warehouse and trucking thefts have not only aided in the currently debilitating state of the opioid crisis in the United States, but these thefts also aid the black market in the illegal sale of diverted prescription drugs. Due to the lack of security measures, vulnerability of the truck drivers, their rigs, and the value of the cargo being transported, pharmaceutical theft is a lucrative opportunity for organized crime. The case presented here describes the issues within the pharmaceutical industry as companies must deal with "last mile" cargo thefts. Daltexpharma represents a synthesized, hypothetical example of a pharmaceutical firm that must develop policies to deal with such potential thefts in its supply chain. Although a fictitious company, the case realistically details the important factors to consider in establishing strong security practices that may be necessary for a pharmaceutical company operating in today's environment. In order to protect the integrity and security of the authors' case notes, particularly for use in an academic setting, the Journal's editor will maintain control of them. They may be obtained by faculty upon presenting their request to the Editor.

Keywords: Daltexpharma; pharmaceutical; theft; security practices

Amy Anderson was hired in 2019 as the new Logistics Manager for Daltexpharma, a small pharmaceutical producer outside Dallas, Texas, and began reviewing the company's logistics approach for its products. Although the company's product line is narrow, it produces several very expensive drugs that have been in strong demand because of their success in treating hypertension. The drugs have a high premium price because of their patent protection and outstanding performance. Daltexpharma hired Amy from the soft goods retail sector, so she has had to quickly get up the learning curve for her new pharmaceutical products. In studying the sector and Daltexpharma's logistics approach, Amy began to have concerns that the company may not be adequately responding to a significant issue in the industry - that of merchandise theft during product transit.

Corresponding author: Nile M. Khanfar, PhD, MBA

Associate Professor

Department of Sociobehavioral and Administrative Pharmacy College of Pharmacy - Palm Beach

Nova Southeastern University

11501 N. Military Trail, Palm Beach Gardens, FL 33410

Phone: 561-805-2242; Email: khanfar@nova.edu
Before joining Daltexpharma, Amy initially thought that the nationwide opioid addiction crisis might be the only significant issue facing the pharmaceutical industry. However, she quickly learned that companies are also battling the issue of what has come to be known as "last mile theft" -- transit courier robberies of prescription drugs. Criminals targeting this realm of theft have increased their efforts earnestly since 2006. The implications are widespread among all parties involved. For example, these diverted drugs may be adulterated and suffer extreme deterioration before they are sold and repurchased on the black market. The disruption in the pharmaceutical supply chain has a dramatic ripple effect that is felt within the practice of healthcare at various levels.

Amy's experience in soft goods was that theft normally occurred at the store level, either by shoppers or employees. In stark contrast, the challenge in pharmaceuticals is that considerable theft is occurring during the "last mile" of transit of the product. She had previously never heard of the problem but wanted to be sure her company was not taking any undue risks regarding the issue. Amy's research on the subject showed her just how big a problem thefts had become. Because of the major implications that failure to secure safe shipping could become for the company, the CEO and Board of Directors asked Amy to present a report on the scope of the issue and to identify possible strategies the company might 
need to pursue in order to fully protect their shipments. Although Amy was easily able to detail the problem, she was having less success with recommending how the company should proceed to handle the challenge.

Amy had polished her report to top management and assembled the following information to be presented at the meeting:

\section{REPORT TO MANAGEMENT ON PHARACEUTICAL THEFT}

There is not one pharmaceutical manufacturer in or outside of the United States that sells its product directly to a consumer retail outlet, community pharmacy, or local hospital. This necessitates a middleman known as a wholesale channel partner. The wholesale channel partners and distributors purchase the desired product in bulk for the ultimate sale to other smaller distributors or retail outlets. The product continues to go on throughout a complex supply chain before it will end up in a consumer's hands. Various small trucks typically owned by independent contractors take pharmaceuticals to their final delivery destination. This multitude of courier services hired by wholesalers results in a varied system of patchwork delivery security ("Transportation Statistics Annual Report," 2016). With every transaction within the supply chain, there is risk that the drug supply will become compromised (Buckley, 2013).

According to FBI statistics, since 2007 the number of transit drivers that have been hijacked is exceeding 850 trucks in recent years, and these incidents are only trending up ("Transportation Statistics Annual Report," 2016). The pharmaceutical industry unfortunately has been victimized by cargo theft since the late 1990s. Pharmaceutical couriers, which consists of any transportation company, large or small, are the new "Brinks armored vans." Distribution centers and trucks carrying high-risk shipments of pharmaceuticals are the two largest targets for theft ("Reducing risk in the pharmaceutical supply chain," 2014). Thefts in which delivery drivers are approached and terrorized are most frequent in the last mile of the pharmaceutical supply chain in comparison with all other steps including the involvement of manufacturing, packaging, and the initial steps of distribution from the originating warehouse. Multiple distribution and trucking companies over a vast number of pharmaceutical companies have fallen victim to this unlawful act. These targets serve as vulnerable and appealing opportunities to addicts, drug dealers, and thieves. With some strategy and luck, selecting the right courier with a high value cargo can yield a medicinal value in excess of one million dollars. According to one assessment by a logistics security service company, the pharmaceutical industry has a portion of the highest average loss values in cargo theft history, accounting for up to $98 \%$ of all last-mile cargo thefts between 2013 and 2015. It is clear how a would-be thief would think about this opportunity -- what could be easier than robbing a high value target whose guard receives little to no security training, typically works alone, and rarely carries weapons for personal protection?

These criminal acts are setting off alarms due to the national opioid epidemic the United States is currently facing. For example, the street value of some prescription medications such as Suboxone ${ }^{\circledR}$ (buprenorphine-naloxone), which generally sells for seventeen cents per pill, can skyrocket to twenty dollars a pill when sold illegally. Counterfeit drugs entering the United States are partially due to pharmaceutical cargo thefts. In 2013 these thefts accounted for $9 \%$ of the seizure total for property theft of an intellectual nature in the United States (“Category: Truck Theft," 2016).

A number of years ago, drug manufacturing company, Eli Lilly, became a statistic in this dichotomy. A warehouse owned and operated by Eli Lilly in Connecticut was burglarized by thieves who descended through the roof in 2012, resulted in 49 pallets of pharmaceutical products lost and a whopping $\$ 80$ million in lost pharmaceutical revenue. The thieves made off with controlled prescriptions including Prozac $\AA$, Cymbalta $\AA$, Zyprexa ${ }^{\circledR}$ and Gemzar $\circledR$ ("Authorities Uncover Largest Theft of Prescription Drugs in US History," 2012). The crew responsible for the theft, later known as the "Cuban Mob", were eventually caught while headed south to Miami, Florida, but once these temperature and humidity sensitive products are out of the supply chain, they must be destroyed because it is unknown as to where it's been or how it's been kept ("Category: Truck Theft," 2016). Eli Lilly, targeted a second time, had a transport cargo theft that resulted in $\$ 37$ million in lost product ("Pharmaceutical Cargo Safety: A Public Health Issue," 2013). This ultimately spurred amelioration within the industry; Pharmaceutical Cargo Security Coalition, PCSC. PCSC was organized with an interdisciplinary vision in mind. The team at PCSC is comprised of pharmaceutical industry professionals, government entities, carrier insurance agents, law enforcement professionals and risk mitigation/management advocates to ensure processes and procedures are created and followed to prevent cargo theft. Currently, Amgen, Boehringer Ingelheim, Catalent, Genentech, Johnson \& Johnson, and Novo Nordisk are all members of PCSC. Another entity to thwart cargo theft known as RxPATROL $®$ through Purdue Pharma, was organized. RxPATROL $®$ (Pattern Analysis Tracking Robberies and Other Losses) was born as an initiative to collect, collate, analyze and disseminate pharmacy theft intelligence to law enforcement throughout the United States. It serves as a clearinghouse of data related to pharmaceutical robberies, burglaries, and cargo theft involving controlled substances (Garguilo, 2015). There is also PSI (pharmacy Security Institute), NBSC (National Biopharmaceutical Security Council) and ASIS (American Society of Industry Security). Through the combined efforts between all of these organizations, improved statistics have been observed. In 2009, there were 47 reported thefts with an average of $\$ 4.2$ million dollars in losses per each reported theft, whereas those numbers have since decreased showing in 2013, reported thefts were as low as 23 for the year with an average 
of \$228,000 per theft (Garguilo, 2015). Unfortunately, when statistics were released for 2016, the total volume of pharmaceutical theft again showed a decrease of approximately one-third in comparison to years past, but the average value of the theft increased by $11 \%$ ("Shipping Theft: Challenge and Response", 2017). PCSC even covers reverse distribution, offering a service to pharmacies to process their unused drug inventory and issuing a manufacturers credit or safe disposal. Combined anti-theft efforts in concert with recognizing the need to stay ever vigilant in regard to supplychain distribution disturbances seem to be the answer to this world-wide issue.

In Alabama, thieves posing as Drug Enforcement Agency (DEA) agents scored an exorbitant number of narcotic pharmaceuticals from McKesson; an estimated 1,800 tablets of oxycodone, 300 OxyContin pain pills and methadone that totaled in excess of $\$ 108,000$ in retail prescriptive value. On the street, these pills would sell for more than 100 times the retail price (Cherici, McGinnis, \& Russell, 2011). In 2018, a carrier hauling \$1 million worth of a life-saving cancer medication, Octagam ${ }^{\circledR}$, was stolen from a truck stop in Tennessee ("Truck hauling nearly $\$ 1 \mathrm{M}$ in cancer treatment drugs stolen in Tennessee," 2018). Teva was affected in 2009 incurring a loss of $\$ 11.8$ million involving Copaxone $\AA$, a multiple sclerosis treatment. Novo Nordisk, in 2009 for a \$11 million loss. Astellas, in 2009, for a $\$ 10$ million loss. An unknown pharmaceutical company/unknown trucking company with Lovenox ${ }^{\circledR}$, a blood thinning drug, in 2009 for a loss of \$9 million, GlaxoSmithKline in 2009 for a \$13.3 million loss ("Pharmaceutical Theft", 2017) and an undisclosed pharmaceutical company/transport company for \$2 million dollars in Bartow County, Ga., are just a handful of examples in the United States that plague the history of the pharmaceutical industry supply chain and distribution practices ("Truck hauling nearly \$1M in cancer treatment drugs stolen in Tennessee," 2018).

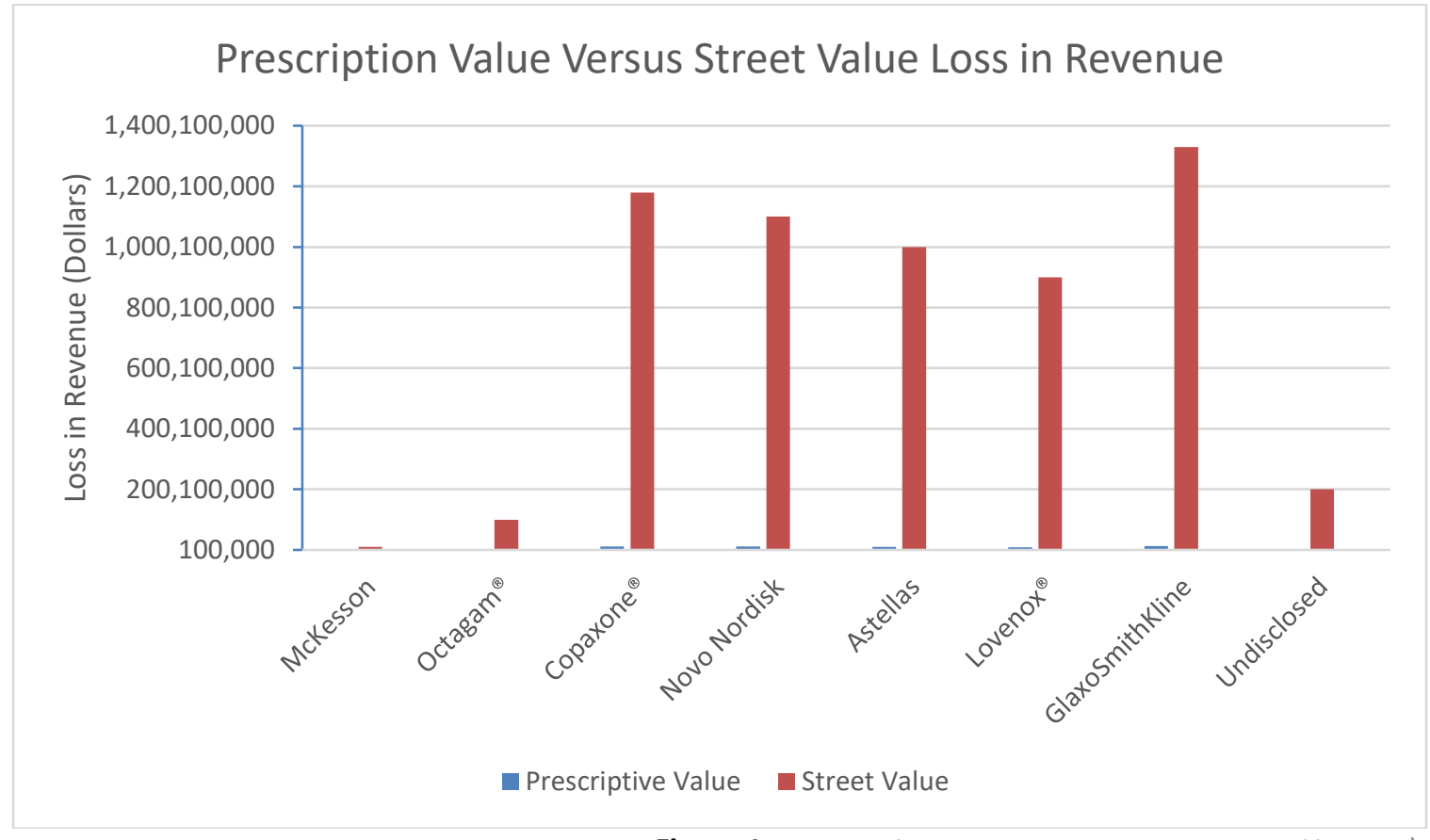

Figure 1

(Cherici, McGinnis, \& Russell, 2011)(FBl.gov)

In 2018, California was noted as having the highest amount of reported cargo theft, accounting for $26 \%$ of thefts in the U.S., with the highest value recorded as being $\$ 5.7$ million. Of the cargo thefts reported in the U.S., $74 \%$ of them were full truckload hauls, located in unsecured parking lots $83 \%$ of the time, and while the vehicle was left unattended $56 \%$. Texas was ranked second for 2018 data, while Florida which was previously ranked second fell to sixth, and New Jersey also noted a decrease in reported cargo thefts for the year. Reported cargo thefts in Illinois and Georgia climbed up the ranking list from 2017 (TAPA, 2019). According to data released by the Incident Information Service, in an article published in Vigilant by TAPA (Transported Asset Protection Association), Europe experienced the highest number in history of reported cargo theft; 3,981 in total, showing an increase of $38.2 \%$ from the previous year. These cargo thefts were estimated to be a total loss of $\in 153.8$ million dollars, of which 214 were considered to be major by the European government accounting for $\in 90$ million in lost and stolen product. It was noted that this was far from the total picture, meaning that these numbers were considerably deflated. European members of TAPA feel as though the realistic numbers are within the billions, and the prospective numbers for 2019 were expected to be even higher.

These criminal efforts are not isolated to large scores of inventories, although they potentially reap the highest return, but rather also involve small delivery trucks delivering to chain 
pharmacies as targets because of what they are transporting. In a recent event, a Chevrolet box truck containing an undisclosed amount of prescription medications was stolen in Sarasota, Florida, outside of a Walgreens, while the driver was inside making a delivery. It was later abandoned several blocks away after being emptied of all contents ("Thieves steal truck delivering drugs to pharmacy in Sarasota," 2019). In 2015, an independent contractor driver delivering medications to a pharmacy in Boynton Beach, Florida, was incapacitated by mace while individuals quickly stole bins of goods nearest to the opened side van door. It was reported that the incident, in its entirety, lasted 12 seconds.

Pharmaceuticals are often targeted by thieves well in advance, and with a buyer already in place to receive the stolen goods, this only complicates an already arduous recovery. According to an article published in Transport Topics, thieves of pharmaceutical products globally are targeting trucks in almost three quarters of thefts recorded by BSI Supply Chain in 2018. (Ronan, para. 3, 2019) The techniques involved in stealing pharmaceuticals vary, but the most common tactic is stealing from trucks by surreptitiously or overtly accessing the payload, a method which accounts for nearly one-third of thefts, following by hijacking and theft from a facility. Cargo thieves, unassumingly, sit outside warehouses or distribution centers observing patterns, learning which trucks carry what products and to which location they will be going to. When the truck that has been targeted leaves the yard, the thieves may do one of two things, attach a GPS tracker on the trailer or simply follow it while in-route to its next stop ("Category: Truck Theft," 2016). Thieves have even become so technologically savvy that they have developed something known as sniffers, that are able to detect tracking devices on cargo trucks. If a sniffer is detected, these unsavory individuals will then employ the use of an on board jammer to scramble the signal that it being sent from the cargo truck itself. Criminals take advantage of the locations that drugs depart from, a point of weakness in the supply chain. 3-D printers have even been utilized to duplicate a trucking container and trailer seals (TAPA, 2019).

The BSI Supply Chain report identified a common inconspicuous threat when it comes to the theft of cargo and other illegal activities against transport personnel and their precious payload: company insiders. It noted that although some organizations have implemented increasingly sophisticated physical, procedural, and cybersecurity measures to protect their assets from external threats, the internal threats remain unidentified. Recruitment of insiders becomes a more lucrative option for those attempting to obtain access to the payload. Financial gain was cited as the single source of motivation in $47 \%$ of all insider criminal cases against companies, and $76 \%$ of the thefts were self-initiated, and not the result of deliberate infiltration or deliberate targeting of the business (Ronan, 2019). According to the Committee on Understanding the Global Public Health Implications of Substandard, Falsified, and Counterfeit Medical Products this is known as pilferage, attritional loss or leakage; the "you owe me" mindset where an employee will "rightfully" through their sense of entitlement, regain what the employer, in their mind "owes" him or her. This can serve as a gateway crime, as scores taken from the employer become larger and larger, and illegal subsidized income grows right along with the amount of stolen goods. There has been a substantial increase in pilfering in the United States and Canada. In 2018, there was a combined 188 thefts that were deemed as pilferage in the third quarter of the year alone. Two pallets can be valued between $\$ 80,000-\$ 100,000$. Pilferage was calculated to be a loss of a whopping $\$ 44.6$ million dollars for 2018, which is a $123.3 \%$ increase from 2017 in this subset of cargo theft ("Cargo Theft: Watch for the Pilferers", 2019).

For all of the thefts that are lawfully reported, there are even more that aren't. Large losses of revenue are claimed which intuitively shows pharmaceutical theft to be a big threat, but low numbers of criminal acts are actually reported. According to a team of researchers at the University of Texas, the reported numbers do not represent a true picture of what is happening (Shepherd, n.d.). An example of this underreporting was detected when a well-known, unnamed, food and drug retailer was required to pay $\$ 3$ million in a settlement for failing to report the theft of drugs that they had incurred. A U.S. Drug Enforcement Administration official stated that this kind of reporting delay is alarming. Others have noted that misreporting by companies may help with shot-term goals, but ultimately, the costs may be surprisingly exorbitant (Park, n.d.). Even at a low average number of $\$ 200,000$ per theft, this would mean a loss to the pharmaceutical industry of up to $\$ 24$ million in stolen goods. With the average loss of $\$ 42$ million per theft, using data from 2009 statistics, the real value of lost cargo could be as high as $\$ 5$ billion. The value of what is underreported seems to be exponentially higher than what is being reported globally per year. (Shepherd, para. 6, n.d.)

Companies may fail to report thefts that they fall victim to in order to avoid scrutiny by the public and/or an increase of their insurance premiums. (Cargo Security News website) Another problem is that reporting systems used by law enforcement, such as the National Crime Information Center ( $\mathrm{NCIC}$ ), lack an appropriate Uniform Crime Report (UCR) code to label cargo theft, which leaves investigators with a difficult judgement call. When reporting a theft, the choices include robbery, extortion/blackmail, burglary/breaking and entering, theft from building, theft from motor vehicle, all other larceny, motor vehicle theft, false pretenses/swindle/confidence game, credit card/automated teller machine fraud, impersonation, wire fraud, embezzlement, and bribery. This highly subjective and potentially confusing reporting process hinders the filing officer's ability to match a crime to the appropriate code to be reported ("Category: Truck Theft," 2016). The true extent of pharmaceutical cargo theft is unknown since it is possibly being categorized under other types of crimes. In 2006, under the PATRIOT ACT renewal, cargo theft was added to the list of 
crimes that must be reported under the Uniform Crime Report, but data has yet to be collected and entered by the agency that is responsible for the UCR, the Federal Bureau of Investigation. (Burges, 2018) Due to these situations not being included in the annual loss numbers reported globally, this becomes an extremely complicated, silent crime. But reporting issues are just one problem when it comes to recovery of stolen cargo. Another prevailing problem is that the supply chain consists of a long and circuitous route that employs a group of underprepared organizations including carriers, brokers, drivers, retailers, and manufacturers. ("Category: Truck Theft," para. 4, 2016). These often undermanned resources make it difficult to truly correlate events in cargo theft at a national level.

Major companies involved in the distribution of pharmaceuticals have been very reluctant to discuss the problems. Three wholesalers with combined revenues of over $\$ 300$ billion dominate the U.S. pharmaceutical market. They have declined to answer specific questions about how often couriers delivering their products are robbed, any security measures undertaken in recent years, and the extent of their reliance on independent contract drivers to deliver their goods. (Armstrong, para. 6, 2016) For example, Cardinal Health has said only that the company maintains robust safety measures to ensure the safe distribution of products. McKesson Corporation has declined to answer questions for security reasons and AmerisourceBergen has not provide responses to questions about theft. (Armstrong, para. 6, 2016)

The pharmaceutical industry operates what has been described as one of the world's most complex and opaque supply chains. It is characterized as an industry that is heavily regulated, with rules and prices that vary from country to country, which generates "a web of legitimate, quasi-legitimate and illegitimate trade" (Patton, para. 1, 2019). A prescription medication moves from manufacturer to several distributors and even "repackagers" before it ends up at a retail pharmacy to be counted and dispensed to a patient. Due to all of the pitstops along the way, it occludes the transparency of the process and diversion and/or counterfeit products enter into the supply chain. It has even been noted that unknowingly some wholesale distributors of pharmaceuticals products have purchased their own stolen goods from the organizations that stole from them initially (Conlon, 2016). A study conducted in 2011 determined that if a cargo theft was executed, and the price of the goods inside, for something as simple and unnecessary as digital cameras, were to be valued at $\$ 200,000.00$, the ripple-effect losses made the direct loss look minimal. The total loss would take on a toll in an additional \$2 million dollars in sales, multiplying the original loss by a factor of 10 , in order to make up for the direct loss of $\$ 200,000.00$. The sales ultimately must aid in recuperating the expedited shipping of replacement product, and repayment of taxes among other concerns for the manufacturing company (Category: Truck Theft, n.d.).

This ripple effect is due to the direct disruption in the supply chain. The effects are not only felt financially but logistically as well. The originating loss triggers other indirect impact losses that travel downstream of the supply chain, felt by not only the manufacturer, but the consumer as well since these thefts translate to the burden of higher retail prices. The cost to the business is exponentially higher than the value of what is lost, and more often than not ancillary costs wind up in the millions (“Shipping Theft: Challenge and Response, 2017).

Pharmaceuticals that have been targeted and stolen pose a number of risks to the supply chain. It is amazingly easy for consumers to unknowingly purchase these drugs online. The pharmaceuticals that leave the proper distribution system are known as diverted drugs (Buckley, 2013). Internet domains are purchased and kept by transnational criminal networks who promise that these stolen diverted medications are being sourced from Canada, but ship from other countries in small parcels through international mail (D.H.S., 2018). When the supply chain is affected due to transport cargo theft, this potentially unveils shortage issues to the consumer. Consumers may look to the internet to find the prescriptions they need. This poses an immediate and dangerous risk. Medications that have been attained through theft have not been stored properly or may have been adulterated with hazardous substances (D.H.S., 2018). For example, insulin, must not experience a temperature excursion for stability and effectiveness during patient use. These diverted drugs pose a very serious risk to public health when they do not work as intended or worsen a patient's disease state due to drug resistance. If the property is located and seized by authorities before it reaches its final destination, it must be destroyed due to potential tampering or chemical degradation leading to a sub-standardization of the product itself, affecting not only the consumer but the pharmaceutical company alike. With these two proceeding risks in mind, consumer confidence may be negatively affected in a particular brand, leading to reputational brand concerns, and overall safety in regard to a particular class of medicinal products must be taken into account. This presents an ethical dilemma to the pharmaceutical manufacturer, in addition to the destruction of the immediate pharmaceutical product involved in the theft, companies have no choice but to spend millions of dollars issuing recalls and destroying legitimate product that has reached the shelves of community pharmacies due to unfortunately sharing the same lot number as the stolen product.

According to the U.S. Drug Enforcement Agency and Department of Justice, the street value of controlled substances far surpasses the prescriptive value when dispensed from a licensed pharmacy within the states (See Table 1). 


\begin{tabular}{|c|c|c|}
\hline Item & Prescriptive Value & Street Value \\
\hline Dilaudid $\circledast 4 \mathrm{mg}$ & $\$ 0.44$ & $\$ 15.00-\$ 20.00$ \\
\hline Fentanyl (per patch) & $\$ 7.58$ & $\$ 10.00$ \\
\hline Hydrocodone & $\$ 0.31$ & $\$ 1.00-\$ 5.00$ \\
\hline Methadone & $\$ 0.17$ & $\$ 10.00$ \\
\hline Methylphenidate & $\$ 0.96$ & $\$ 5.00$ \\
\hline Morphine & $\$ 0.55$ & $\$ 30.00$ per 10 tablets \\
\hline MS Contin $\AA 60 \mathrm{mg}$ & $\$ 0.81$ & $\$ 20.00$ \\
\hline Oxycodone 80mg & $\$ 0.36$ & $\$ 12.00-\$ 40.00$ \\
\hline Oxycontin $® 80 \mathrm{mg}$ & $\$ 4.44$ & $\$ 35.00-\$ 50.00$ \\
\hline Promethazine \& Codeine (per pint) & $\$ 0.09$ & $\$ 200-\$ 600$ \\
\hline Tussionex® (per pint) & $\$ 4.09$ & $\$ 30.00-\$ 40.00$ \\
\hline Diazepam 5mg & $\$ 0.25$ & $\$ 1.00-\$ 2.00$ \\
\hline Vicodin $®$ ES & $\$ 0.57$ & $\$ 5.00$ \\
\hline Xanax $® 2 \mathrm{mg}$ & $\$ 1.01$ & $\$ 3.00-\$ 5.00$ \\
\hline
\end{tabular}

Source: D.O.J., 2013

In some instances, medications obtained through the gray market were marked up on average $650 \%$. The largest market offers on drugs were the ones that were necessary to treat critically ill patients. The gray market, or parallel market, is an unofficial, unauthorized, and/or unintended supply channel that is not vetted by the original manufacturer. In a market where the products are scarce or in short supply, due to environmental effects or manufacturing delays, gray markets take the opportunity to evolve and sell the scarce/short supply item at any price the market will bend to, thus capitalizing on the critical shortage (Cherici, McGinnis, \& Russell, 2011). Some prescription drugs have exceeded the $650 \%$ markup and gone as high as $4,533 \%$ markup during times of shortage (Cherici, McGinnis, \& Russell, 2011). There is a myriad of safety issues to be considered when purchasing these pharmaceuticals in marketing flyers from the gray market. The drugs from previous cargo thefts made their way back into the supply chain through gray market sources. In one instance, once the stolen goods had been unknowingly dispensed for patient use, it was discovered to be less efficacious insulin resulting in uncontrolled blood sugar levels (Cherici, McGinnis, \& Russell, 2011). When reported to the D.E.A., it is typical that the entire lot that is correlated to the stolen lot must be destroyed meaning an exponential loss that goes beyond what was stolen. If the stolen property is never recovered, it can be sold illegally on the streets, or online to those who do not possess prescriptions. They may also still be within the investigational stages, meaning the FDA has not yet approved them for human use/consumption that now, may be sold under false pretenses.

Due to the dangers of ingesting fake drugs, thousands of people worldwide die every year and ultimately costs the pharmaceutical industry approximately $\$ 46$ billion a year in profit loss (Patton, 2018). The loss in revenue that is experienced by the pharmaceutical company is devastating. The World Health Organization (W.H.O.) reported in a study that diverted drugs represent more than $10 \%$ of global sales (Patton, 2018).

\section{REFERENCES}

1. 5 Weaknesses in the Drug Distribution Chain. Institute of Medicine. 2013. Countering the Problem of Falsified and Substandard Drugs. Washington, DC: The National Academies Press. doi: 10.17226/18272. Accessed: Aug 11, 2019.

2. Armstrong, D. (2016, August 8). Pharmacy delivery vans targeted by drug thieves. Retrieved from https://www.statnews.com/2015/12/22/pharmacydelivery-vans-targeted/. Accessed: Aug 11, 2019

3. Burges, D. (2012). Cargo theft, loss prevention, and supply chain security. Retrieved from

https://ebookcentral.proquest.com. Accessed: August 10, 2019.

4. Category: Truck Theft. (2016). Retrieved from https://www.transportsecurity.com/news/category/trucktheft. Accessed: August 10, 2019.

5. Cherici, C., McGinnis, P., \& Russell, W. (2011). Buyer beware: Drug shortages and the gray market. Retrieved from http://www.anco-online.org/GrayMarketAnalysisPremier.pdf. Accessed: August 11, 2019.

6. Committee on Understanding the Global Public Health Implications of Substandard, Falsified, and Counterfeit Medical Products; Board on Global Health; Institute of Medicine; Buckley GJ, Gostin LO, editors. Countering the Problem of Falsified and Substandard Drugs. Washington (DC): National Academies Press (US); 2013 May 20. Available from:

https://www.ncbi.nlm.nih.gov/books/NBK202530/. Accessed: August 13, 2019.

7. Conlon, B. (2016). The Dynamics of Domestic and International Cargo Theft. Science and Technology Law Review, 19(4), 296-406. Retrieved from https://scholar.smu.edu/cgi/viewcontent.cgi?article=1212\& context=scitech. Accessed: August 13, 2019.

8. D.H.S. (2018). Treats to Pharmaceutical Supply Chain. Retrieved from https://www.dhs.gov/sites/default/files/publications/2018 AEP Threats to Pharmaceutical Supply Chains.pdf. Accessed: August 10, 2019. 
9. D.O.J. (2013). Pharmaceutical Supply Chain Reporting and Thefts. Retrieved from

https://www.deadiversion.usdoj.gov/mtgs/pharm awaren ess/conf 2013/august 2013/san diego/herold.pdf. Accessed: August 15, 2019.

10. Garguilo, L. (2015). Physical Security for The Pharma Supply Chain. Retrieved from https://www.outsourcedpharma.com/doc/physicalsecurity-for-the-pharma-supply-chain-0001. Accessed: August 13, 2019.

11. Overdrive. (2018, May 14). Truck hauling nearly $\$ 1 M$ in cancer treatment drugs stolen in Tennessee. Retrieved from https://www.overdriveonline.com/truck-haulingnearly-1m-in-cancer-treatment-drugs-stolen-in-tennessee/. Accessed: August 10, 2019.

12. Park, M. (n.d.). Armed Robbery Growing Problem for Truckers. Retrieved from https://abcnews.go.com/Business/wireStory/us-industrialproduction-slipped-01-march-62429055. Accessed: August 11, 2019.

After her presentation to top management, Amy was peppered with questions from the group regarding what she would recommend to counter the problem she had described. Although she had some ideas, she was reluctant to share them without further analysis. The board requested that she make another presentation within two weeks to propose realistic strategies for dealing with the potential threat of "last mile" cargo theft.

\section{Brief Case Teaching Note}

The Daltexpharma case is appropriate for advanced undergraduate or graduate courses in Business (e.g., Logistics) and Pharmacy (e.g., Pharmacy Business, Pharmacy Regulatory Affairs, or Pharmacy Management, where different aspects could be emphasized. In Pharmacy Business, students could utilize the application of risk mitigation, the importance of brand reputation, consumer confidence, and how to appropriately alert the public without negative effects and/or outcomes. In a Pharmacy Regulatory Affairs course, it is important to understand the role of the FDA, DEA, in concert with the pharmaceutical company and the effect on the pharmaceutical company's process and procedures for handling incidents such as these. A business logistics course could focus on appropriate supply chain management decisions when facing a potential high-threat environment for product security during transport.

The following discussion questions are appropriate to guide case discussion:

1. What process and procedural improvements can be made at the levels of warehouse distribution and trucking?

2. What kind of improvements can be made on a security level to ensure that cargo is not only tamper-proof, but less identifiable to criminals?
3. What is the origin of security threats to transit cargo? Please identify the holes that ultimately allow for security threats to be an issue throughout the process of preparing for shipment and transit?

4. Briefly discuss process and procedural improvements that can be done at the pharmaceutical distribution level to thwart future criminals or capture data once the product is recovered from its outset.

5. What are some loss mitigation steps that can be taken to ensure all is being done to protect the cargo while in the supply-chain distribution process?

In order to protect the integrity of the Daltexpharma case for use in academic settings, the authors' case notes providing answers to discussion questions have not been provided to readers. However, they are available upon request to the corresponding author. Please submit your request by identifying your faculty status in an email or on your academic letterhead. 